\title{
DO H. PYLORI STATUS AND SMALL INTESTINAL BACTERIAL OVERGROWTH DETERMINE THE CLINICAL COURSE OF CHRONIC ACTIVE GASTRITIS IN PATIENTS WITH TYPE 2 DIABETES MELLITUS?
}

DOI: 10.36740/WLek202006127

\author{
Tetiana 0. Radionova, Igor M. Skrypnyk, Ganna S. Maslova \\ UKRAINIAN MEDICAL STOMATOLOGICAL ACADEMY, POLTAVA, UKRAINE
}

\begin{abstract}
The aim: To define clinical peculiarities of chronic active gastritis in patients with type 2 diabetes mellitus (T2DM) considering Helicobacter pylori (HP) status and small intestinal bacterial overgrowth (SIBO).

Materials and methods: 172 patients with chronic active gastritis were enrolled in the study, 92 out of them had concomitant T2DM. Symptoms were collected with the questionnaire, HP infection was diagnosed with stool antigen test, SIBO was assessed with glucose hydrogen breath test.

Results: $87.5 \%$ ( $n=70$ ) patients with chronic gastritis without DM had epigastric pain, however those with T2DM reported pain only in $41.3 \%$ ( $n=38$ ) cases. 0ther symptoms included: nausea, bloating, early satiety, postprandial fullness, heartburn, belching and vomiting. HP infection in patients with chronic gastritis and concomitant T2DM is significantly associated with symptoms of epigastric pain $(O R=2.78,95 \% \mathrm{Cl} 0.92-8.41)$, bloating $(O \mathrm{R}=3.92,95 \% \mathrm{Cl} 1.40-10.99)$, nausea $(0 \mathrm{R}=2.32,95 \% \mathrm{Cl} 0.85-0.6 .30)$, postprandial fullness $(\mathrm{OR}=1.45,95 \% \mathrm{Cl} 0.54-3.87)$ and belching $(\mathrm{OR}=1.01,95 \% \mathrm{Cl} 0.32-3.16)$, whereas SIBO - with bloating $(\mathrm{OR}=8.82,95 \% \mathrm{Cl} 2.88-27.01)$, nausea $(0 \mathrm{R}=5.15$, 95\% Cl 1.88-14.10) and belching (OR=2.53,95\% Cl 0.67-9.52).

Conclusions: Patients with T2DM and chronic active gastritis report epigastric pain significantly less than non-diabetics. HP infection probably plays a prominent role in development of epigastric pain in patients with T2DM. Additionally, HP is linked to SIBO, which may lead to bloating, belching and nausea onset.
\end{abstract}

KEY WORDS: type 2 diabetes mellitus, chronic gastritis, Helicobacter pylori, small intestinal bacterial overgrowth, gastrointestinal symptoms

Wiad Lek. 2020;73(6):1223-1228

\section{INTRODUCTION}

Comorbidity is always a challenge for diagnostics and therapy of the vast majority of diseases. Clinicians have to consider all the possible interactions, common pathways, and issues that may occur as a result of overlap between two or more disorders. Considering Type 2 diabetes mellitus (T2DM) as an epidemic in the XXI century [1,2], it becomes obvious that different comorbidities associated with T2DM need comprehensive study. As estimated by the International Diabetes Federation in 2019, there are 463 million people with DM worldwide, and this number is increasingly growing [3]. Type 1 diabetes mellitus (T1DM) has always been in the focus of researches, but the data on T2DM is quite limited and controversial. Longstanding T2DM results in complications that may affect any organ in human organism through neuropathy and angiopathy.

It goes without saying that disturbances in gastrointestinal (GI) function may affect the pharmacodynamics of oral hypoglycemic agents and postprandial glucose level. In this case «vicious circle» may be formed: impaired motor function of GI tract may slow down the transit and further absorption of nutrients (including glucose). In turn the postprandial blood glucose profile will be shifted, which dissociates time of plasma glucose concentration peak and time-related mechanisms of action of hypoglycemic agents. In this case it becomes difficult to maintain the target glucose level within normal ranges, and poorly controlled DM predisposes to complications development, including gastrointestinal $[4,5]$.

Thus, impaired blood glucose levels may predetermine gastrointestinal disorders in patients with DM. On the other hand, gastrointestinal diseases may affect as postprandial blood glucose level as pharmacodynamic of oral hypoglycemic agents. Described mechanisms highlight the importance of GI functioning correction in terms of DM management, enhancing in this way adequate glycemic control.

One of the most common GI pathologies is chronic gastritis, which is often left underestimated in clinical practice, however it may result in peptic ulcer and gastric cancer [6]. Some studies suggest that patients with T2DM are more predisposed to stomach cancer $[7,8]$ than those without DM. In addition T2DM is a risk factor for peptic ulcer bleeding [9] and delayed ulcer healing [10]. Hence, the comorbidity between T2DM and chronic gastritis is considered to be a relevant aspect of clinical research.

It is well known that Helicobacter pylori (HP) is the leading etiological factor of gastritis, peptic ulcer and stomach 
cancer. As well stress factors are thought to play important role in exacerbations of chronic gastritis and peptic ulcer [11]. The prevalence of HP infection among patients with DM is debatable. However, some studies suggest the link between HP infection and T2DM, claiming that prevalence of $\mathrm{HP}$ among patients with T2DM is much higher than in non-diabetics [12-14] and patients with T1DM [15]. The group of Chinese researchers found opposite relationship: people with positive HP status are under the risk of DM [16]. The relevance of HP diagnostics in patients with DM is also supported by better glycemic control after HP-eradication [17], which is probably realized through pro-inflammatory factors decrease [18].

The first step of chronic gastritis diagnostics in patients with T2DM is based on clinical symptoms. Recently one descriptive, cross-sectional study showed that $91.4 \%$ patients with DM express mainly such GI symptoms as flatulence, retrosternal pain, belching, postprandial fullness, and constipation [19]. It is typical for patients with diabetes not to have pain syndrome in case of GI disorders, which often complicates timely diagnostics. In addition, severe forms of gastritis and ulcer disease are often followed by mild dyspeptic syndrome [20]. That is why it is important to understand clinical manifestation of GI diseases in patients with DM to make an accurate diagnosis and prescribe proper treatment in time. However, there are no studies, focused on clinical features of stomach disorders in patients with DM depending on their HP status.

Nowadays much attention is paid to GI microbiome. Despite the fact that HP is considered to be the major etiological factor of many stomach diseases, a lot of investigations of GI microbiota, including gastric, are being performed. Even though the data is limited, the role of microbiota impairment was established even in carcinogenesis [21] and bacterial overgrowth was found to promote gastric cancer [22]. Summarizing the role of microbiota in gastric disorders and its probable influence on glycemic control in patients with DM [23], GI bacteria in patients with DM and GI disorders need to be assessed more attentively.

\section{THE AIM}

To characterize the upper GI symptoms of chronic active gastritis in patients with T2DM in comparison to non-diabetic patients and define the peculiarities of chronic gastritis in patients with T2DM considering HP infection and small intestinal bacterial overgrowth (SIBO).

\section{MATERIALS AND METHODS}

The current multi-centered, descriptive, cross-sectional study was conducted in 2017-2019. 172 patients with clinically, endoscopically and histologically confirmed chronic active gastritis were enrolled. 92 participants had T2DM (diabetic group) and 80 didn't have DM or impaired glycemic states (control non-diabetic group). T2DM was previously diagnosed and defined as fasting plasma glucose $(\mathrm{FPG}) \geq 7.0 \mathrm{mmol} / \mathrm{L}$ or glycated haemoglobin (HbAlc) $\geq 6.5 \%$ [3]. The diagnosis of chronic gastritis was made on the basis of esophagogastroduodenoscopy (EGD) with biopsy (7 mucosal biopsy samples were analysed). Subjects with oncopathology, autoimmune disorders, inflammatory bowel diseases, acute infections, severe renal and hepatic diseases and peptic ulcer at the moment of investigation were excluded prior to the study. To define HP-infection stool antigen test (SATs) was carried out. SIBO was diagnosed with glucose hydrogen breath test (HBT) when there was a rise in hydrogen more than $12 \mathrm{ppm}$ above the basal level after glucose ingestion [24]. The symptoms were collected with the questionnaire aiming to register the presence of the next upper GI symptoms: epigastric pain, bloating, early satiety, heartburn, nausea, vomiting, postprandial fullness, belching. Additional information on study population, glycemic profile, hypoglycemic therapy, concomitant pathology and complications of DM was obtained from the latest patients' medical records.

Ethical norms were adhered: all enrolled patients were fully informed about the research and informed consents were obtained before the study. The study project was approved by the bioethics committee of Ukrainian Medical Stomatological Academy, Poltava, Ukraine (order number $156,20.06 .17)$.

Data reported as mean \pm standard deviation and number (\%). Statistical analysis to assess the link between events was conducted with the use of odds ratio (OR) parameter. For statistical analysis software STATA/IC v.16 for Windows (Stata Corp LLC, 2019) was applied.

\section{RESULTS}

\section{CHARACTERISTICS OF STUDY POPULATION}

The total of 172 patients with endoscopically and histologically confirmed chronic active gastritis participated in the research. Those who did not meet the criteria of inclusion were previously excluded. All patients were subdivided onto 2 groups: group I $(n=92)$ - patients with chronic active gastritis and T2DM; group II $(n=80)$ - control group of patients with chronic active gastritis without DM.

The gender distribution in the group I was: male $-68,5 \%$ $(\mathrm{n}=63)$, female $-31.5 \%(\mathrm{n}=29)$; in the group II: male $57.5 \%(n=46)$, female $-42.5 \%(n=34)$. Male gender is considered to be linked to the chronic gastritis in patients with T2DM (OR=1.61, 95\% CI 0.86-2.99). The mean age of the patients in the $\mathrm{I}^{\text {st }}$ group was $61.6 \pm 9.0$ years, in the $\mathrm{II}^{\text {nd }}$ group $-54.0 \pm 13.5$ years.

The mean level of FBGL in patients with T2DM was $7.3 \pm 2.4 \mathrm{mmol} / \mathrm{L}, \mathrm{HbA} 1 \mathrm{c}-8.7 \pm 2.3 \%$. About $39.1 \%(\mathrm{n}=36)$ of patients with T2DM and chronic gastritis had decompensated T2DM, 83.7\% $(n=77)$ were diagnosed with diabetic angiopathy and diabetic neuropathy. The glycemic control was maintained in 59,8\% $(n=55)$ patients with peroral hypoglycemic agents (metformin, glyclazide, glibenclamid), in $18.5 \%(\mathrm{n}=17)$ cases - with insulin therapy, and $21,7 \%(n=20)$ of patients controlled their glucose levels with dietary and lifestyle modifications. 
Table I. Distribution of symptoms of chronic gastritis in patients with T2DM ( $n=92)$ depending on HP-status and SIBO.

\begin{tabular}{|c|c|c|c|c|}
\hline \multirow{2}{*}{$\begin{array}{c}\text { Symptoms } \\
\text { (total number of cases in group) }\end{array}$} & \multicolumn{2}{|c|}{ HP status } & \multicolumn{2}{|c|}{ SIBO status } \\
\hline & $\begin{array}{l}H P^{\prime \prime}+" \\
(n=71)\end{array}$ & $\begin{array}{l}H P^{\prime \prime} " \\
(n=21)\end{array}$ & $\begin{array}{l}\text { SIBO “+” } \\
(n=69)\end{array}$ & $\begin{array}{l}\text { SIBO"_" } \\
(n=23)\end{array}$ \\
\hline $\begin{array}{l}\text { Epigastric pain } \\
\qquad(\mathrm{n}=38)\end{array}$ & $\begin{array}{l}46.5 \% \\
(n=33)\end{array}$ & $\begin{array}{l}23.8 \% \\
(n=5)\end{array}$ & $\begin{array}{l}40.6 \% \\
(n=28)\end{array}$ & $\begin{array}{l}43.5 \% \\
(n=10)\end{array}$ \\
\hline $\begin{array}{c}\text { Bloating } \\
(n=54)\end{array}$ & $\begin{array}{l}66.2 \% \\
(n=47)\end{array}$ & $\begin{array}{l}33.3 \% \\
(n=7)\end{array}$ & $\begin{array}{l}71.0 \% \\
(n=49)\end{array}$ & $\begin{array}{l}21.7 \% \\
(n=5)\end{array}$ \\
\hline $\begin{array}{l}\text { Early satiety } \\
\qquad(n=44)\end{array}$ & $\begin{array}{l}38.0 \% \\
(n=27)\end{array}$ & $\begin{array}{l}80.9 \% \\
(n=17)\end{array}$ & $\begin{array}{l}46.4 \% \\
(n=32)\end{array}$ & $\begin{array}{l}52.2 \% \\
(n=12)\end{array}$ \\
\hline $\begin{array}{c}\text { Heartburn } \\
(\mathrm{n}=37)\end{array}$ & $\begin{array}{l}40.9 \% \\
(n=29)\end{array}$ & $\begin{array}{c}38.1 \% \\
(n=8)\end{array}$ & $\begin{array}{l}37.7 \% \\
(n=26)\end{array}$ & $\begin{array}{l}47.8 \% \\
(n=11)\end{array}$ \\
\hline $\begin{array}{c}\text { Nausea } \\
(n=62)\end{array}$ & $\begin{array}{l}71.8 \% \\
(n=51)\end{array}$ & $\begin{array}{l}52.4 \% \\
(n=11)\end{array}$ & $\begin{array}{l}76.8 \% \\
(n=53)\end{array}$ & $\begin{array}{l}39.1 \% \\
(n=9)\end{array}$ \\
\hline $\begin{array}{l}\text { Vomiting } \\
(n=6)\end{array}$ & $\begin{array}{l}5.6 \% \\
(n=4) \\
\end{array}$ & $\begin{array}{l}9.5 \% \\
(n=2)\end{array}$ & $\begin{array}{l}5.8 \% \\
(n=4)\end{array}$ & $\begin{array}{l}8,7 \% \\
(n=2)\end{array}$ \\
\hline $\begin{array}{l}\text { Postprandial fullness } \\
\qquad(\mathrm{n}=46)\end{array}$ & $\begin{array}{l}52.1 \% \\
(n=37)\end{array}$ & $\begin{array}{c}42.9 \% \\
(n=9)\end{array}$ & $\begin{array}{l}49,3 \% \\
(n=34) \\
\end{array}$ & $\begin{array}{l}52.2 \% \\
(n=12)\end{array}$ \\
\hline $\begin{array}{l}\text { Belching } \\
(n=22)\end{array}$ & $\begin{array}{l}23.9 \% \\
(n=17)\end{array}$ & $\begin{array}{l}23.8 \% \\
(n=5)\end{array}$ & $\begin{array}{l}27.5 \% \\
(19)\end{array}$ & $\begin{array}{l}13.0 \% \\
(n=3)\end{array}$ \\
\hline
\end{tabular}

\section{PREVALENCE OF SYMPTOMS}

Upper GI symptoms of chronic gastritis in the patients of the $\mathrm{I}^{\text {st }}$ group with T2DM differed from the patients in the II $^{\text {nd }}$ group. The main contrast was observed regarding abdominal pain: $87.5 \%(\mathrm{n}=70)$ patients with chronic gastritis without DM had epigastric pain, however those with T2DM reported pain only in $41.3 \%(n=38)$ of cases. Thus, T2DM was found to increase the risk of atypical presentation of gastritis without epigastric pain syndrome $(\mathrm{OR}=$ 8.91, 95\%CI 4.17-19.05). On the contrary, patients with chronic gastritis and T2DM reported dyspeptic symptoms more commonly than patients without T2DM: bloating $58.7 \%(n=54)$ vs $40.0 \%(n=32)$, early satiety $47.8 \%(n=44)$ vs $15.0 \%(n=12)$, heartburn $40.2 \%(n=37)$ vs $30.0 \%(n=24)$, nausea $67.4 \%(n=62)$ vs $52.5 \%(n=42)$, vomiting $6.5 \%$ $(\mathrm{n}=6)$ vs $1.5 \%(\mathrm{n}=1)$, postprandial fullness $50.0 \%(\mathrm{n}=46)$ vs $11.3 \%(n=9)$ respectively. However, belching was presented more among patients without T2DM $42.5 \%(\mathrm{n}=34)$ vs $23.9 \%(n=22)$.

\section{SYMPTOMS AND HP INFECTION}

According to the obtained results, HP infection was detected in $77 \%(n=71)$ patients with chronic gastritis and concomitant T2DM (group I), while only $60 \%(n=48)$ of those without DM had this bacterium (group II).

After T2DM patients of the I ${ }^{\text {st }}$ group $(n=92)$ were additionally subdivided onto HP-positive $(\mathrm{n}=71)$ and HP-negative cases $(n=21)$, the next data was received. Epigastric pain, bloating and nausea were mainly reported by patients with chronic HP-positive gastritis and T2DM in comparison to non-diabetic patients, namely $46.5 \%(\mathrm{n}=33)$ vs $23.8 \%(n=5), 66.2 \%(n=47)$ vs $33.3 \%(n=7), 71.8 \%(n=51)$ vs $52.4 \%(\mathrm{n}=11)$ respectively (Table I). HP infection in patients with chronic gastritis and concomitant T2DM is significantly associated with symptoms of epigastric pain ( $\mathrm{OR}=2.78,95 \% \mathrm{CI} 0.92-8.41)$, bloating $(\mathrm{OR}=3.92$, 95\%CI 1.40-10.99), nausea (OR=2.32, 95\%CI 0.85-0.6.30), postprandial fullness $(\mathrm{OR}=1.45,95 \% \mathrm{CI} 0.54-3.87)$ and belching ( $\mathrm{OR}=1.01,95 \% \mathrm{CI} 0.32-3.16)$, whereas there is no association with early satiety, heartburn and vomiting.

\section{SYMPTOMS AND SIBO}

In our study we found that SIBO was another common state in patients with chronic gastritis and T2DM (group I), as $75 \%(n=69)$ of them had positive HBT with glucose. Patients with chronic gastritis without DM (group II) were diagnosed with SIBO only in $41.3 \%(n=33)$ cases.

After T2DM patients of the $I^{\text {st }}$ group $(n=92)$ were additionally subdivided onto SIBO-positive $(n=69)$ and SIBO-negative subjects $(n=23)$, we detected that those with SIBO express vomiting in 5.8\% $(\mathrm{n}=4)$ cases, belching - in $27.5 \%(n=19)$, heartburn - in $37.7 \%(n=26)$, epigastric pain - in $40.6 \%(n=28)$, early satiety - in $46.4 \%(n=32)$, postprandial fullness - in $49.3 \%(\mathrm{n}=34)$, bloating - in $71.0 \%$ $(n=49)$, nausea - in $76.8 \%(n=53)$ cases (Table I). SIBO in patients with chronic gastritis and T2DM is strongly associated with such symptoms as bloating $(\mathrm{OR}=8.82$, 95\%CI 2.88-27.01), nausea (OR=5.15, 95\%CI 1.88-14.10) and belching $(\mathrm{OR}=2.53,95 \% \mathrm{CI} 0.67-9.52)$.

\section{ASSOCIATION OF HP AND SIBO}

As mentioned before, SIBO has been diagnosed in 75\% $(n=69)$ diabetic patients of the $\mathrm{I}^{\mathrm{st}}$ group. Out of them $79.7 \%(\mathrm{n}=55)$ were HP-positive and $20.3 \%$ were $(n=14)$ HP-negative. HP infection in patients with T2DM and chronic gastritis was 
statistically significantly linked to SIBO (OR=1.72, 95\%CI 0.59-4.98). While in the II ${ }^{\text {nd }}$ (control) group such association was absent, only $41.3 \%(n=33)$ patients had SIBO, $57.6 \%$ $(n=19)$ out of them were HP-positive and $42.4 \%(n=14)-$ HP-negative $(\mathrm{OR}=0.84,95 \% \mathrm{CI}$ 0.34-2.09). Hence, patients with T2DM and HP-positive gastritis are at the risk of SIBO.

\section{DISCUSSION}

It is known, that GI symptoms are prevalent in T2DM $[5,19,25,26]$, but the exact mechanisms of this process are still unknown. Results of some studies suggest that GI symptoms predominate in women with DM more than in men [19,25-27], but these studies were focused on symptoms itself, not on specific GI pathology. Speaking specifically about gastritis, Yang et al. observed more severe forms of inflammation exactly in male patients with T2DM, not in females [28]. In the current study upper GI symptoms among patients with T2DM were also linked to the male sex, which may be explained by distinctive features of men's lifestyle and presence of harmful habits, however these aspects were not studied in the current research.

The most common complications of DM are diabetic angiopathy and diabetic neuropathy, including autonomic neuropathy [3]. In such conditions multiple organs, as well stomach, may suffer from lack of blood supply and proper innervation, resulting in GI disturbances [29]. 83.7\% of patients with T2DM in our study were diagnosed with these complications, that in turn could negatively influence on gastric function and GI motility in general. Neuropathy probably affects pain perception, that was shown in our study, as T2DM significantly decreases epigastric pain onset in patients with chronic active gastritis and T2DM in comparison to non-diabetics (87.5\% vs $41.3 \%)$. Khoshbaten et al. reported even lower incidence of abdominal pain among the patients with DM - 31\% [5], nonetheless in our study we included patients with confirmed gastric pathology, which can explain the higher rates of pain. Regarding the fact that chronic gastritis is typically followed by pain syndrome, we can assume that T2DM places patients at risk of atypical chronic gastritis without pain syndrome. At the same time, subjects with T2DM express such symptoms as bloating, early satiety, heartburn, nausea, vomiting and postprandial fullness more often than patients without DM. Our results corelate with Asgharnezhad's et al. research [19], besides belching, which in our study was reported more frequently among the patients without T2DM than with T2DM (42.5\% vs $23.9 \%$ ). It is important to notice that delayed gastric emptying is often followed by nausea [25]. All these findings should be considered while managing patients with GI pathology and concomitant T2DM, as untimely made diagnosis may lead to more dramatic consequences, such as stomach ulcer, bleeding, cancer etc., especially in terms of comorbidity with DM [7-9]. This idea was also supported by the research of Boehme et al., reporting high prevalence of silent severe gastritis and other stomach diseases in patients with T2DM [20].

A wide range of studies has demonstrated that patients with DM are at a greater risk of HP infection [12-16], however the results certainly depend on the country where the research has been carried out and epidemiological situation with HP in the region. Some researchers have proved that HP infection is highly associated with T2DM, however its prevalence widely vary from $59 \%$ to $75 \%$ [13-15]. The analysis in current study showed that HP infection was the main cause of chronic gastritis in patients with T2DM (77\%). It is difficult to assert in scope of our study whether $\mathrm{DM}$ is associated with HP infection or not, as only patients with chronic active gastritis were included. However, we noticed that HP probably plays significant role in development of epigastric pain in patients with T2DM (which is not generally typical for patients with T2DM, as mentioned above), as $46.5 \%$ HP-positive diabetic patients reported this complaint. Diabetes itself may lead to dyspepsia and gastropathy, so probably its combination with HP differs symptomatically and pathogenetically. Thus, it is possible to conclude that patients with T2DM and epigastric pain should be checked for HP infection, as in this case the probability of positive result is much higher, than if the patient has no epigastric pain.

Another peculiarity of chronic gastritis in patients with T2DM is commonly diagnosed SIBO (75\% vs $41.3 \%$ non-diabetic cases). In contrast, some literature data suggest that patients with T1DM are diagnosed with SIBO in 37.8\% cases [30]. Such symptoms as bloating, belching and nausea in patients with chronic gastritis and T2DM are significantly associated as with HP infection, as with SIBO, which has been diagnosed in 77.5\% HP-positive cases and 66.7\% HP-negative cases. It was also confirmed that HP infection is significantly associated with SIBO in patients with chronic gastritis and T2DM (OR=1.72, 95\%CI 0.59-4.98). Such relationship is observed probably due to GI hypomotility that result in bacterial overgrowth in different parts of GI tract [31]. SIBO may be also triggered by such factors as: stomach hypoacidity and decreased bile flow. These factors took place in our study among diabetic cohort: the stomach acidity according to the EGD protocol was $>2.1$ in $71.7 \%(n=66)$; and $63.0 \%(n=58)$ had concomitant biliary disorders. Summarizing the risk factors for SIBO in patients with T2DM, it was estimated that hypoacidity predisposes to SIBO onset $(\mathrm{OR}=2.87,95 \% \mathrm{CI}$ 1.08-7.60). The role of T2DM in SIBO development was also highlighted in one of American studies, where DM was found to be a risk factor for SIBO in patients with chronic pancreatitis [32].

As known, the main source of gas production in GI tract are bacteria, which produce it during their metabolism [24]. This may explain the relationship between SIBO and such symptoms as bloating and belching in patients with chronic gastritis and T2DM.

\section{CONCLUSIONS}

Patients with T2DM have some clinical peculiarities of chronic gastritis, that may be linked not only to diabetic neuro- and angiopathy, but also GI microbiota. Patients with T2DM report epigastric pain significantly less, than 
non-diabetics, which makes T2DM the risk factor for atypical development of chronic gastritis without pain syndrome. In addition, patients with T2DM and chronic gastritis express nausea, bloating, early satiety, postprandial fullness, heartburn and vomiting more often than those without DM.

HP infection probably plays a prominent role in development of epigastric pain in patients with T2DM, as despite of low incidence of abdominal pain among diabetic patients, HP-positive subjects still report this complaint. Additionally, HP is linked to SIBO, which in turn may lead to bloating, belching and nausea onset. Thus, GI bacteria state might predetermine the spectrum of symptoms in patients with chronic gastritis associated with T2DM.

\section{REFERENCES}

1. 'Standl E., Khunti K., Hansen T.B. et al. The global epidemics of diabetes in the 21st century: Current situation and perspectives. Eur J Prev Cardiol. 2019;26(2):7-14. doi: 10.1177/2047487319881021.

2. Jaacks L.M., Siegel K.R., Gujral U.P. et al. Type 2 diabetes: A 21st century epidemic. Best Pract Res Clin Endocrinol Metab. 2016 Jun;30(3):331-43. doi: 10.1016/j.beem.2016.05.003.

3. International Diabetes Federation. IDF Diabetes Atlas, 9th edn. Brussels, Belgium: 2019. Available at: https://www.diabetesatlas.org.

4. Rayner C.K., Samsom M., Jones K.L. et al. Relationships of upper gastrointestinal motor and sensory function with glycemic control. Diabetes Care. 2001;24(2):371-81.

5. Khoshbaten M., Madad L., Baladast M. et al. Gastrointestinal signs and symptoms among persons with diabetes mellitus. Gastroenterol Hepatol from Bed to Bench. 2011;4(4):219-23.

6. Sipponen P., Maaroos H.I. Chronic gastritis. Scand J Gastroenterol. 2015;50(6):657-67.

7. Oberaigner W., Ebenbichler C., Oberaigner K. et al. Increased cancer incidence risk in type 2 diabetes mellitus: Results from a cohort study in Tyrol/Austria. BMC Public Health. 2014 0ct 10;14:1058. doi: 10.1186/1471-2458-14-1058.

8. Wang M., Hu R.Y., Wu H. Bin et al. Cancer risk among patients with type 2 diabetes mellitus: A population-based prospective study in China. Sci Rep. 2015;5(June):1-7. doi:10.1038/srep11503.

9. Peng Y.L., Leu H.B., Luo J.C. et al. Diabetes is an independent risk factor for peptic ulcer bleeding: A nationwide population-based cohort study. J Gastroenterol Hepatol. 2013;28(8):1295-9.

10. Lim J.H., Kim S.G., Choi J. et al. Risk factors of delayed ulcer healing after gastric endoscopic submucosal dissection. Surg Endosc. 2015;29(12):3666-73.

11. Tarasenko, L.M.,Skrypnik, I.N., Neporada K.S. Parallelizm metabolicheskih narushenij v tkanyah zheludka i parodonta pri stressornyh vozdejstviya [Simultaneous stress-induced metabolic changes in the stomach and periodontium]. Bull Exp Biol Med. 2000;130(7):639-41. (In Russian)

12. Ebule I., Djune.F, Njeambosay B. et al. Association of Helicobacter Pylori Infection and Diabetes Mellitus Type 2 Subjects in Yaounde Cameroon Using a Panel of Serum Biomarkers (PGIl, HplgG):A Case Control Study. J Clin Gastroenterol Treat.2017;3(4):5-9.

13. Tawfeeq R., Amin Z., Nuraddin S. et al. Relationship between type II diabetes mellitus and Helicobacter pylori infection in Erbil city. Zanco J Med Sci. 2019;23(1):43-50.

14. Wali N., Waheed A., Aslam M. Association of helicobacter pylori infection in patients suffering from Type 2 Diabetes mellitus. Pakistan J Med Heal Sci. 2018;12(2):535-7.
15. Li J.Z., Li J.Y., Wu T.F. et al. Helicobacter pylori infection is associated with type 2 diabetes, not type 1 diabetes: An updated metaanalysis. Gastroenterol Res Pract. 2017;2017:5715403. doi: 10.1155/2017/5715403.

16. Wan Z., Song L., Hu L. et al. Helicobacter pylori infection is associated with diabetes among Chinese adults. J Diabetes Investig. 2020;11(1):199-205.

17. Cheng K.P., Yang Y.J., Hung H.C. et al. Helicobacter pylori eradication improves glycemic control in type 2 diabetes patients with asymptomatic active Helicobacter pylori infection. J Diabetes Investig. 2019;10(4):1092-101.

18. Bonfigli A.R., Boemi M., Festa R. et al. Randomized, double-blind, placebo-controlled trial to evaluate the effect of Helicobacter pylori eradication on glucose homeostasis in type 2 diabetic patients. Nutr Metab Cardiovasc Dis. 2016;26(10):893-8.

19. Asgharnezhad M., Joukar F., Fathalipour M. et al. Gastrointestinal symptoms in patients with diabetes mellitus and non-diabetic: A cross-sectional study in north of Iran. Diabetes Metab Syndr Clin Res Rev. 2019;13(3):2236-40. doi: 10.1016/j.dsx.2019.05.028.

20. Boehme M.W.J., Autschbach F., Ell C. et al. Prevalence of silent gastric ulcer, erosions or severe acute gastritis in patients with type 2 diabetes mellitus-a cross-sectional study. Hepatogastroenterology. 2007 Mar;54(74):643-8.

21. Dias-Jácome E., Libânio D., Borges-Canha M. et al. Gastric microbiota and carcinogenesis: The role of non-Helicobacter pylori bacteria - A systematic review. Rev Esp Enfermedades Dig. 2016;108(9):530-40.

22. Wang L., Zhou J., Xin Y. et al. Bacterial overgrowth and diversification of microbiota in gastric cancer. Eur J Gastroenterol Hepatol. 2016;28(3):261-6.

23. Grasset E., Burcelin R. The gut microbiota to the brain axis in the metabolic control. Rev Endocr Metab Disord. 2019;20(4):427-38.

24. Gasbarrini A., Corazza G.R., Gasbarrini G. et al. Methodology and indications of $\mathrm{H2}$-breath testing in gastrointestinal diseases: The Rome consensus conference. Aliment Pharmacol Ther. 2009 Mar 30;29(1):1-49. doi: 10.1111/j.1365-2036.2009.03951.x.

25. Chedid V., Brandler J., Vijayvargiya P. et al. Characterization of Upper Gastrointestinal Symptoms, Gastric Motor Functions, and Associations in Patients with Diabetes at a Referral Center. Am J Gastroenterol. 2019;114(1):143-54. doi:10.1038/s41395-018-0234-1.

26. Du Y.T., Rayner C.K., Jones K.L. et al. Gastrointestinal symptoms in diabetes: Prevalence, assessment, pathogenesis, and management. Diabetes Care. 2018;41(3):627-37.

27. Brown L.K., Xu J., Freedman B.I. et al. Symptoms Suggestive of Gastroparesis in a Community-Based Cohort of European Americans and African Americans with Type 2 Diabetes Mellitus. Dig Dis Sci. 2019;(0123456789). doi: 10.1007/s10620-019-05974-Z.

28. Yang Y.J., Wu C.T., Ou H.Y. et al. Male non-insulin users with type 2 diabetes mellitus are predisposed to gastric corpus-predominant inflammation after H. pylori infection. J Biomed Sci. 2017;24(1):82. doi: 10.1186/s12929-017-0389-x.

29. Ghadiri-Anari A., GholamiS., Sheyda E. et al. Does diabetic microvascular complications affect gastrointestinal symptoms? Acta Med Iran. 2019;57(3):156-9.

30. Adamska A., Nowak M., Piłaciński S. et al. Small intestinal bacterial overgrowth in adult patients with type 1 diabetes: Its prevalence and relationship with metabolic control and the presence of chronic complications of the disease. Pol Arch Med Wewn. 2016;126(9):628-34. 
31. Lee Y.Y. Systemic disorders that affect gastrointestinal motility. Clinical and Basic Neurogastroenterology and Motility. In: Lee YY, Haque MM, Lawenko RM et al. Clinical and Basic Neurogastroenterology and Motility. Elsevier Inc; 2020. p. 601-618.

32. Lee A.A., Baker J.R., Wamsteker E.J. et al. Small Intestinal Bacterial Overgrowth is Common in Chronic Pancreatitis and Associates With Diabetes, Chronic Pancreatitis Severity, Low Zinc Levels, and Opiate Use. Am J Gastroenterol. 2019;114(7):1163-71.

Current study was the part of research work "Improvement of diagnostic approaches and treatment optimization of gastrointestinal diseases associated with disorders of other systems" (number of state registration 0117 U 000300).

\section{ORCID and contributorship:}

Tetiana O. Radionova - 0000-0002-3429-5455 B,C,D

Igor M. Skrypnyk - 0000-0002-3426-3429 A,E,F

Ganna S. Maslova - 0000-0002-4729-1736 ${ }^{\text {B,C }}$

\section{Conflict of interest:}

The Authors declare no conflict of interest.

\section{CORRESPONDING AUTHOR} Tetiana 0. Radionova

Department of Internal Medicine No 1, Ukrainian Medical Stomatological Academy Shevchenka street 23, 36000 Poltava, Ukraine tel: +380669661683

e-mail: tetiana.radionova.1991@gmail.com

Received: 06.03 .2020

Accepted: 04.05 .2020 